\title{
Modeling and experimental verification of the thin multi-electrode piezoceramic bars' forced vibrations
}

\author{
Bezverkhy O., Zinchuk L., Karlash V. \\ S. P. Timoshenko Institute of Mechanics, The National Academy of Sciences of Ukraine \\ 3, Nesterov str., 0305\%, Kyiv, Ukraine
}

(Received 24 June 2016)

\begin{abstract}
This paper is devoted to analysis of the multi-electrode piezoceramic bars' forced vibrations. Analytical model is built for a thin and narrow piezoelectric ceramic bar with three pairs of divided electrodes on the upper and lower main surfaces. The formulae for input admittance, characteristic (resonant and anti-resonant) frequencies as well as for transform ratio are obtained. The fundamental modes of vibrations of thin piezoelectric bar and their odd and even overtones are studied. A new experimental simple technique with additional commutation permits to study many resonators' parameters: admittance, impedance, phase angles, power components etc. Experiments have been carried out with TsTBS-3 bar-prism $70.3 \times 8.1 \times 6.8 / 7.1 \mathrm{~mm}$ size. It is established that a high electromechanical coupling may be obtained for bar's longitudinal overtones by means of the electrode coating dividing and anti-phase electrical loading. In partly shorted electrodes case, not only odd but even longitudinal modes can be induced, which are absent for full electrodes case.
\end{abstract}

Keywords: multi-electrode piezoceramic bar, forced vibrations, electromechanical coupling, input admittance, transformation ratio.

2000 MSC: $74-05,74 \mathrm{~F} 15,74 \mathrm{H} 45$

UDC: $534.1: 537.226 .86: 539.3$

\section{Introduction}

Modern piezoelectric components, while performing similar or better than electromagnetic ones, can be effectively used for device miniaturization [1-3]. Since piezoelectric ultrasonic motors and transformers have 1/10-th size comparing to equivalent-power-level electromagnetic devices and do not produce electromagnetic noise, piezoelectric components have been replacing with electromagnetic analogs. The industry is interested in even higher efficiency and forces a research towards more power dense piezoelectric technologies, while scaling sizes go down. However, the power density in piezoelectric devices is still limited by material's inherent losses which stems from the microscopic domain dynamics, resulting in generation of heat. Therefore, to advance the device miniaturization, it is necessary to consider the energy loss mechanisms.

When an alternating electric field is applied to a non-center symmetric crystal or polarized piezoceramic sample, mechanic vibrations are induced, which with an appropriate frequency cause mechanical resonance with great strains and stresses. A phenomenon of strain increasing due to accumulated electric energy is known as a piezoelectric resonance [4-7, etc]. Both the direct piezoelectric effect - a conversion of mechanical energy into electrical energy, and the inverse piezoelectric effect - a conversion of electric energy into mechanical energy, are linear physical phenomena with respect to the induced fields.

Piezoelectric ceramic elements' vibrations are characterized by a great electromechanical coupling between electric fields and elastic displacements or stresses. It is possible to calculate any amplitude with accounting the energy losses only [5-10]. The analytic solutions for fundamental modes of the 
electro-elastic vibrations of simple geometric form bodies such as bars, rods, disks, circular or cylindrical rings, etc. [5-7] are used in standards for determination real parts of the dielectric, elastic and piezoelectric coefficients.

A very thin electrode coating on sample surfaces serves to polarize and to induce mechanic vibrations simultaneously. It is basically anticipated that a piezoelectric resonator with full electrode has its maximum electromechanical coupling factor (EMCF) on fundamental modes of vibration. However, sometimes it is not possible to impose a full electrode on the piezoelectric resonator faces due to the mechanical clamping or electrical insulation of the resonator. Small facet on the piezoelectric ceramic ring or disc edges is one of the examples of such electrode deposition deficiency [11-13]. There is also possibility of EMCF enhancement by the divided electrode pattern optimization [14-17].

The work [10] is devoted to modeling of the loss-energy piezoceramic resonators by Van-Dyketype electric equivalent networks with passive elements. It was shown that when piezoelectric sample is excited by constant voltage, the instantaneous power in sample increases at resonance frequency in many times with respect to off-resonant case. When sample is excited by constant current the instantaneous power decreases at resonance frequency in the same ratio. Thus, the reason of admittance curve nonlinearity at constant voltage and its absence at a constant current is higher or lower level of an instantaneous power.

Imaginary parts of the dielectric, elastic and piezoelectric coefficients usually are determined on maxima/minima admittances [4-8]. Very important role in energy losses belongs to mechanic quality factor $Q$, which is different for resonance and anti-resonance [18].

This paper is devoted to analysis of the multi-electrode piezoceramic bars' forced vibrations. Analytical model is constructed for a thin and narrow piezoelectric ceramic bar with three pairs of divided electrodes on the upper and lower main surfaces. The fundamental modes of vibrations of the thin piezoelectric bar and their odd and even overtones are studied. A new simple experimental technique with additional computation permits to study many resonators' parameters: admittance, impedance, phase angles, power components etc. Experiments were provided with TsTBS-3 bar-prism of $70.3 \times 8.1 \times 6.8 / 7.1 \mathrm{~mm}$ size. It was established that high electromechanical coupling may be obtained for bar's longitudinal overtones by means of the electrode coating dividing and anti-phase loading. In shorted part electrodes can be excited by not only odd but even longitudinal modes, which are absent for full electrodes case.

The results of computer simulation and experimental data are in good agreement.

\section{Analytic relations for admittance of the thin piezoceramic bars with divided elec- trodes}

Piezoelectric bars with transversal polarization became already a "touchstone" in many experimental researches because their vibrations are described by simple mathematical formulae, and the first overtone lies far on frequency from fundamental resonance [6-15]. The mechanical and electric values of these structures are coupled between itself by so-called the transversal coefficient of electromechanical coupling $(\mathrm{EMCF}) k_{31}$ and this is a reason why the longitudinal vibrations of such bars are known as $k_{31}$ mode $[1-3,18]$.

In Refs [8-10] it was shown that the piezoelectric resonator's admittance may be presented in calculations as imaginary conductivity of the inter-electrode sample capacitance $C_{0}$ multiplied by the ratio of anti-resonance determinant $\Delta_{a}(\kappa)$ to resonance $\Delta(\kappa)$ determinant

$$
Y_{p e}=j \omega C_{0} \frac{\Delta_{a}}{\Delta_{r}}=\frac{j 2 \pi f_{01} C_{0} \kappa}{\kappa_{01}} \frac{\Delta_{a}}{\Delta_{r}}=j a_{0} \kappa \frac{\Delta_{a}}{\Delta_{r}}, \quad\left(a_{0}=\frac{2 \pi f_{01} C_{0}}{\kappa_{01}}\right) .
$$

In (1) $j$ is the imaginary unit, $\omega$ is the angular frequency, $f_{01}$ is the resonant frequency, $\kappa_{01}$ and $\kappa$ are the dimensionless resonant frequency and the running dimensionless frequency, which are dependent on geometric sample's form. 
Let us look at a simple piezoelectric ceramic system (thin and narrow piezoelectric ceramic bar), in which three pairs of the various electrodes are axially symmetric (Fig. 1). Electrodes are shown as thick lines. The central electrode $I$ has a size $-a \leqslant y \leqslant a$, the right part $I I$ lies on $a \leqslant y \leqslant l$, and the left part $I I I$ has a length $-l \leqslant y \leqslant-a$. All notations coincide with Refs [7-10]. Electric exciting field, mechanical displacement and stress in bar's parts are $E_{i}, U_{i}$ and $\sigma_{i}(i=1,2,3)$ accordingly. The input voltage is $V_{0} e^{j \omega t}$, the multiplier $e^{j \omega t}$ hereinafter is omitted.

The boundary conditions are the following: both edges of the bar are free from stresses, mechanical displacements and stresses are continuous on the dividing lines of electrodes, furthermore vibrations are symmetric $U_{y i}(y)=-U_{y i}(-y)$

$$
\begin{gathered}
\sigma_{y 3}(-l)=\sigma_{y 2}(l)=0, \quad U_{y 1}(a)=U_{y 2}(a), \quad U_{y 1}(0)=0, U_{y 1}(-a)=U_{y 3}(-a), \\
\sigma_{y 1}(a)=\sigma_{y 2}(a), \quad \sigma_{y 1}(-a)=\sigma_{y 3}(-a) .
\end{gathered}
$$

Constitutive and motion equations are of the forms:

$$
\varepsilon_{y i}=\frac{\partial U_{y i}}{\partial y}=s_{11}^{E} \sigma_{y i}+d_{31} E_{x i}, \quad D_{x i}=\varepsilon_{33}^{T} E_{x i}+d_{31} \sigma_{y i}, \quad \frac{d^{2} U_{y i}}{d y^{2}}+\rho \omega^{2} s_{11}^{E} U_{y i}=0 .
$$

Solutions of the motion equation, deformations and stresses can be expressed as

$$
\begin{gathered}
U_{y i}=A_{i} \sin k y+B_{i} \cos k y, \quad \varepsilon_{y i}=A_{i} k \cos k y-B_{i} k \sin k y, \quad\left(k^{2}=\rho \omega^{2} s_{11}^{E}\right), \\
\varepsilon_{y i}=s_{11}^{E} \sigma_{y i}+d_{31} E_{x i}, \quad \sigma_{y i}=\frac{\varepsilon_{y i}}{s_{11}^{E}}-\frac{d_{31} E_{x i}}{s_{11}^{E}}=\frac{A_{i} k \cos k y-B_{i} k \sin k y}{s_{11}^{E}}-\frac{d_{31} E_{x i}}{s_{11}^{E}} .
\end{gathered}
$$

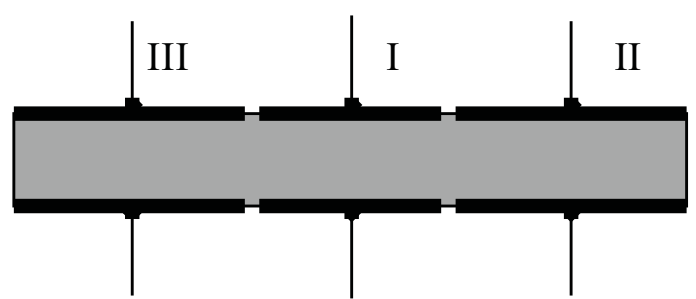

Fig. 1. Schema of the multi-electrode piezoceramic bar.

On the base (1) - (5) we can obtain

$$
\begin{gathered}
A_{1}=\frac{d_{31} E_{2}}{k \cos k l}+\frac{d_{31}\left(E_{1}-E_{2}\right)}{k \cos k l} \cos (k l-k a), \quad A_{2}=\frac{d_{31} E_{2}}{k \cos k l}+\frac{d_{31}\left(E_{1}-E_{2}\right)}{k \cos k l} \sin k l \sin k a, \\
B_{2}=\frac{d_{31}\left(E_{1}-E_{2}\right)}{k \cos k l} \cos k l \sin k a, \quad A_{3}=A_{2}+\frac{d_{31}\left(E_{3}-E_{2}\right)}{k \cos (k l-k a)} \cos k l, \\
B_{3}=-A_{3} \frac{\cos k l}{\sin k l}+\frac{d_{31} E_{3}}{k \sin k l}, \quad B_{1}=0 .
\end{gathered}
$$

It must be noted here that for anti-phase loading case, when $E_{2}=-E_{1}\left(E_{2}=E_{3}\right)$, these relations coincide with the formulae (6) of Ref [14].

Electric charge and current for $I$ and $I I$ bar's regions are obtained after integration of the electrical displacement [6]

$$
\begin{aligned}
& Q_{1}=\int_{S} D_{x 1} d S=\varepsilon_{33}^{T} S_{1} E_{1}\left[1-k_{31}^{2}+\frac{k_{31}^{2}}{\gamma \kappa} \frac{\Delta_{1}}{\Delta} \sin \gamma \kappa\right], \quad I_{1}=-j \omega C_{1}^{T} V_{1}\left[1-k_{31}^{2}+\frac{k_{31}^{2}}{\gamma \kappa} \frac{\Delta_{1}}{\Delta} \sin \gamma \kappa\right], \\
& Q_{2}=\varepsilon_{33}^{T} S_{2} E_{1}\left[\left(1-k_{31}^{2}\right) \mu_{2}+\frac{k_{31}^{2}}{(\kappa-\gamma \kappa)} \frac{\Delta_{0}}{\Delta}\right], \quad I_{2}=-j \omega C_{2}^{T} V_{1}\left[\left(1-k_{31}^{2}\right) \mu_{2}+\frac{k_{31}^{2}}{(\kappa-\gamma \kappa)} \frac{\Delta_{0}}{\Delta}\right],
\end{aligned}
$$


where

$$
\begin{gathered}
\Delta=\cos \kappa, \quad \Delta_{1}=\mu_{2}+\left(1-\mu_{2}\right) \cos (\kappa-\gamma \kappa), \quad \Delta_{2}=\mu_{2}+\left(1-\mu_{2}\right) \sin \gamma \kappa \sin \kappa \\
\Delta_{3}=\left(1-\mu_{2}\right) \sin \gamma \kappa \cos \kappa, \quad \Delta_{0}=\Delta_{2}(\sin \kappa-\sin \gamma \kappa)+\Delta_{3}(\cos \kappa-\cos \gamma \kappa), \\
\kappa=k l, \quad \gamma=a / l, \quad \mu_{2}=\frac{E_{2}}{E_{1}}, \quad E_{1}=-\frac{V_{1}}{\delta}, \quad E_{2}=-\frac{V_{2}}{\delta}, \quad k_{31}^{2}=\frac{d_{31}^{2}}{s_{11}^{E} \varepsilon_{33}^{T}} \\
C_{1}^{T}=\frac{\varepsilon_{33}^{T} S_{1}}{\delta}, \quad S_{1}=2 a \cdot 2 b, \quad \delta=2 h, \quad C_{2}^{T}=\frac{\varepsilon_{33}^{T} S_{2}}{\delta}, \quad S_{2}=(l-a) \cdot 2 b, \\
C_{0}^{T}=\frac{\varepsilon_{33}^{T} 2 l \cdot 2 b}{\delta}=C_{1}^{T}+2 C_{2}^{T}, \quad C_{1}^{T}=\gamma C_{0}^{T}, \quad C_{2}^{T}=\frac{1-\gamma}{2} C_{0}^{T} .
\end{gathered}
$$

The full resonator's current $I$ and its admittance $Y$ depend on a way of an electrical loading. When parts $I I$ and $I I I$ have equal potential we may to write down

$$
\begin{aligned}
I & =I_{1}+2 I_{2}=-j \omega C_{1}^{T} V_{1}\left[1-k_{31}^{2}+\frac{k_{31}^{2}}{\gamma \kappa} \frac{\Delta_{1}}{\Delta} \sin \gamma \kappa\right]-j 2 \omega C_{2}^{T} V_{1}\left[\left(1-k_{31}^{2}\right) \mu_{2}+\frac{k_{31}^{2}}{(\kappa-\gamma \kappa)} \frac{\Delta_{0}}{\Delta}\right] \\
& =-j \omega C_{0}^{T} V_{1}\left\{\gamma\left[1-k_{31}^{2}+\frac{k_{31}^{2}}{\gamma \kappa} \frac{\Delta_{1}}{\Delta} \sin \gamma \kappa\right]+(1-\gamma)\left[\left(1-k_{31}^{2}\right) \mu_{2}+\frac{k_{31}^{2}}{(\kappa-\gamma \kappa)} \frac{\Delta_{0}}{\Delta}\right]\right\}, \\
Y & =\frac{I}{V_{1}}=-j \omega C_{0}^{T}\left\{\gamma\left[1-k_{31}^{2}+\frac{k_{31}^{2}}{\gamma \kappa} \frac{\Delta_{1}}{\Delta} \sin \gamma \kappa\right]+(1-\gamma)\left[\left(1-k_{31}^{2}\right) \mu_{2}+\frac{k_{31}^{2}}{(\kappa-\gamma \kappa)} \frac{\Delta_{0}}{\Delta}\right]\right\} .
\end{aligned}
$$

The resonant and anti-resonant frequencies are determined from the following relations

$$
\begin{aligned}
\Delta(\kappa) & =\cos (\kappa)=0, \\
\left(1-k_{31}^{2}\right) \Delta \gamma_{1}+k_{31}^{2}\left(\Delta_{1} \sin \gamma \kappa+\Delta_{0}\right) / \kappa & =0, \quad\left(\gamma_{1}=\gamma+(1-\gamma) \mu_{2}\right) .
\end{aligned}
$$

As it is concluded from (11), (12), the resonant frequencies depend on $\kappa$ only, but the anti-resonant frequencies are determined by $k_{31}$ too.

The multi-electrode piezoelectric ceramic bar with one or a number of free electrodes exhibits both resonator and transformer features. The transformation ratio for no load work may be obtained from the expressions (7), when $I_{1}$ or $I_{2}$ is to level zero

$$
\begin{gathered}
K_{t 1}=\frac{1}{\mu_{21}}, \quad \mu_{21}=\frac{\left(k_{31}^{2}-1\right) \gamma \kappa \cos \kappa}{k_{31}^{2} \sin \gamma \kappa(1-\cos (\kappa-\gamma \kappa))}-\frac{\cos (\kappa-\gamma \kappa)}{1-\cos (\kappa-\gamma \kappa)}, \quad K_{t 2}=\mu_{22}, \\
\mu_{22}=\frac{z_{2}}{z_{2}-z_{1}}, \quad z_{1}=k_{31}^{2}+\left(1-k_{31}^{2}\right)(1-\gamma) \kappa \cos \kappa, \quad z_{2}=k_{31}^{2} \sin \gamma \kappa(1-\cos (\kappa-\gamma \kappa)) .
\end{gathered}
$$

The transformation ratio $K_{t 1}$ and the multiplier $\mu_{21}$ correspond to free (open) central electrode case, while the transformation ratio $K_{t 2}$ and the multiplier $\mu_{22}$ correspond to the case when edge electrodes remain free. When output electrodes are connected with loading resistance $R_{L}$ the transformation ratio may be derived from

$$
I_{i}=U_{i} / R_{L i}
$$

In (14) $I_{i}$ is current in $i$-th electrode circuit, $U_{i}$ is the voltage on $i$-th electrode and $R_{L i}$ is the resistance of loading resistor in $i$-th electrode circuit.

\section{Experimental technique and samples for investigation of the thin piezoceramic bars' forced vibrations}

The simple electrical network, which is shown in Fig. 2, permits us to measure with a great accuracy three voltage drops: on piezoelement $U_{p e}$, on measurement circuit input $U_{i n}$ and on loading resistor 
$U_{R}$ in a wide range around resonance and anti-resonance by single voltmeter $V$ and commutation of loading resistor or studying sample [8,9]. Voltmeter's input (point " $C$ ") may be jointed with the voltage divider output (point " $A$ ") or common connection of resistor and sample (point " $B$ "). In top switcher $S_{1}$ position, as shown on Fig. 2, the voltmeter measures $U_{R}$ voltage. When switcher $S_{1}$ is in lower position, the voltmeter measures $U_{p e}$ voltage. This schema can realize three various loading conditions: 1) the constant sample current, 2) the constant sample voltage, 3) the constant input voltage. Based on the experimental data the amplitude-frequency characteristics (AFCh) for different physical parameters of a resonator or transformer can be plotted in figures.

Three measured voltages $U_{p e}, U_{R}$, and $U_{i n}$ create a peculiar characteristic triangle [8,9] and angles between its sides may be calculated with using the cosine law as

$$
\cos \alpha=\frac{U_{p e}^{2}+U_{R}^{2}-U_{i n}^{2}}{2 U_{p e} U_{R}}, \quad \cos \beta=\frac{U_{i n}^{2}+U_{R}^{2}-U_{p e}^{2}}{2 U_{i n} U_{R}}, \quad \cos \gamma=\frac{U_{i n}^{2}+U_{p e}^{2}-U_{R}^{2}}{2 U_{i n} U_{p e}} .
$$

In (15), the angle $\alpha$ formed by the sides $U_{R}$ and $U_{p e}$ characterizes the change of phases between a current and voltage drop in piezoelement. The angle $\beta$, which is formed by the sides $U_{i n}$ and $U_{R}$, responses for a phase shift between output voltage of generator and consumable current. And the angle $\gamma$ formed by the sides $U_{i n}$ and $U_{p e}$ characterizes the difference of phases between output voltage of generator and voltage drop at piezoelement. The admittance (or full conductivity) characterizes sample's possibility to conduct elec-

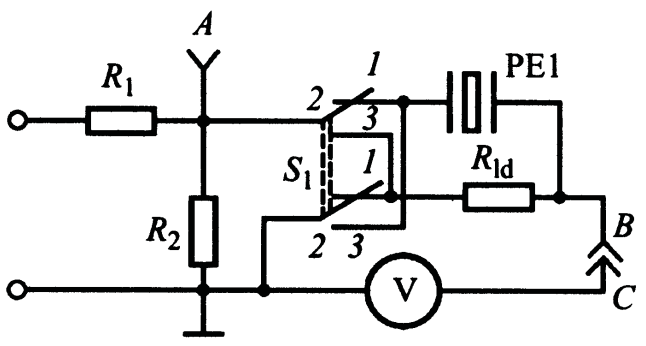

Fig. 2. Schema of the experimental technique. tric current and is determined as a ratio of the sample current to the sample voltage. This parameter is convenient for analysis near piezoelectric sample resonance where it reaches a maximum value. In our experiments, in parallel to generator's output or coordinating divider $R_{1}, R_{2}$ output the piezoelement $P E l$ and loading resistor $R_{l d}$ in series were connected. The inter-electrode capacitance $C_{0}$ and the dielectric loss tangent $\tan \delta=\varepsilon_{33 m}$ were measured by alternative current bridge using. The voltage $U_{R}$ is proportional to the electrical current $I_{p e}$ in the resistor and the sample

$$
U_{R}=I_{p e} R_{l d} .
$$

The ratio of current to voltage is determined as admittance

$$
Y_{p e}=\frac{I_{p e}}{U_{p e}}=\frac{U_{R}}{R_{l d} U_{p e}} .
$$

The product of sample current by the sample voltage is determined as instantaneous power

$$
P_{p e}=U_{p e} I_{p e}=\frac{U_{R} U_{p e}}{R_{l d}} .
$$

For piezo-transformer regime case, the input electrodes of the piezoceramic bar were connected in parallel to $R_{2}$ resistor, then voltages $U_{\text {in }}$ and $U_{\text {out }}$ were measured and transformation ratio was determined as

$$
K_{t}=\frac{U_{\text {out }}}{U_{\text {in }}} .
$$

The amplitude-frequency characteristics (AFC) of admittances, impedances, instant powers and phase angles for several bar's longitudinal modes of vibrations at various loading schemas were plotted and compared with calculated ones. 
Our experiments were provided with three equal-size TsTBS-3 bar-prisms of $70.3 \times 8.1 \times 6.8 / 7.1 \mathrm{~mm}$ with thickness polarization in $20 \div 200 \mathrm{kHz}$ frequency range. The first prism had full electrodes, the second prism had one bilateral central electrode cut and the third prism had two bilateral electrodes cut and three equal-area parts.

\section{Results of the experiments and calculations}

Table 1 demonstrates measured values of inter-electrode capacities and dielectric loss tangents of the three bar-prisms for several loading conditions. The contracted notations S1.1, S2.1, S2.2, S2.3, S3.1 S3.5 denote accordingly: the first prism and full electrodes; the second prism in-phase, anti-phase or shorted electrodes; the third prism for cases of in-phase, anti-phase or free (open) inner or outer electrodes. In S3.3 schema all lower electrodes were connected together, central upper electrode was free and capacity between outer upper and all lower electrodes was measured. In S3.4 schema the capacity between central upper and all lower electrodes was measured. At last, in S3.5 schema the capacity between central and outer upper electrodes was measured. In lower table row the ratios $C_{i} / C_{0}$ of measured capacities to capacities for full electrodes are presented.

Table 1. The inter-electrode capacities and dielectric loss tangents of the bar-prisms.

\begin{tabular}{|l|l|l|l|l|l|l|l|l|l|}
\hline Schema & $\mathrm{S} 1.1$ & $\mathrm{~S} 2.1$ & $\mathrm{~S} 2.2$ & $\mathrm{~S} 2.3$ & $\mathrm{~S} 3.1$ & $\mathrm{~S} 3.2$ & $\mathrm{~S} 3.3$ & $\mathrm{~S} 3.4$ & $\mathrm{~S} 3.5$ \\
\hline$C, \mathrm{pF}$ & 1296 & 1300 & 1443 & 780 & 1228 & 1570 & 978 & 561 & 478 \\
\hline $\tan \delta$ & 0.0022 & 0.0026 & 0.0029 & 0.0031 & 0.0022 & 0.003 & 0.0026 & 0.0028 & 0.003 \\
\hline$C_{i} / C_{0}$ & 1.0 & 1.0 & 1.11 & 0.6 & 1.0 & 1.278 & 0.796 & 0.45 & 0.389 \\
\hline
\end{tabular}

The capacitances $C_{1}^{T}, C_{2}^{T}, C_{0}^{T}$ are written in (8), (9) as capacitances of flat condenser when the ratios of areas to thicknesses were multiplied by the dielectric constant $\varepsilon_{33}^{T}$. It may seem that after electrode separation the capacities of obtained parts must relate to the full sample capacity as corresponding areas. It is seen from Table 1 that static capacities for full (S1.1) or in-phase (S2.1 and S3.1) cases differ on $6 \%$ only. In contrast, anti-phase loading with one cut (schema S2.2) increases measured capacity on $11 \%$ and anti-phase loading with two cuts (schema S3.2) increases measured capacity on $28 \%$. In schema S2.3 case, when one half of an electrode coating is shorted, measured capacity is equal to $780 / 1300=0.6$, rather then 0.5 as we must to wait. In schemas S3.3 and S3.4 we may to wait $2 / 3$ and $1 / 3$ from capacity ratios but measured data are higher. At last, in S3.5 schema the capacity relation $C_{i} / C_{0}$ is equal to 0.389 instead zero which is expected. The reason of the observed phenomena lies in additional capacities which appear between electrode's parts because dividing lines are very narrow.

To verify the vibration's modes for one bilateral central electrode cut case and loading schemas S2.1 - S2.3, the piezotransformer transducer method $[6,7,9]$ was applied. Eleven circle-shaped transducers of $3.1 \mathrm{~mm}$ in diameter were divided in electrode coating in the middle of one half of a $70.3 \times 8.1 \mathrm{~mm}$ surface and spaced along the bar as: $0 ; 3.2 ; 6.5 ; 9.5 ; 12.5 ; 15.5 ; 18.7 ; 21.5 ; 25 ; 28.2$ and $32.2 \mathrm{~mm}$ from the its center. Average transducer's capacity between divided transducers and rest electrode coating was equal to $135.2 \pm 13 \mathrm{pF}$. Main reason of the capacity deviation lies in various widths of the dividing bounds. In Refs $[6,7]$ it was shown that piezotransformer transducer potentials are proportional to mechanical stresses in according points and this method permits to study a resonant stress state of piezoceramic samples. Analytical expressions for this bar's case were presented in Ref [17].

Fig. 3 represents the experimental frequency dependences of the input admittance of the one bilateral cut prism for in-phase $(a)$, anti-phase $(b)$ and shorted $(c)$ electrodes cases obtained with (16), (17). Longitudinal modes $L 1, L 3, L 5$ and $L 7$ as well as a number of intensive resonances are observed in frequency range $20 \div 200 \mathrm{kHz}$ for in-phase load case. High-order longitudinal overtones are masked with intensive modes and we must limit them by mode $L 7$ for our prisms. In anti-phase loading case

Mathematical Modeling and Computing, Vol.3, No.1, pp. 1-11 (2016) 
modes $L 2, L 6$ and their weak "satellites" $L 2^{*}, L 6^{*}$ are registered. For shorted electrodes case, not only odd $L 1, L 3, L 5$ modes but even $L 2, L 6, L 2^{*}, L 6^{*}$ longitudinal modes are excited, which are absent for full electrodes case. But mode $L 4$ not registered now. To excite even longitudinal mode $L 4$, the electrode coating must be divided in four equal parts with anti-phase electrical load.

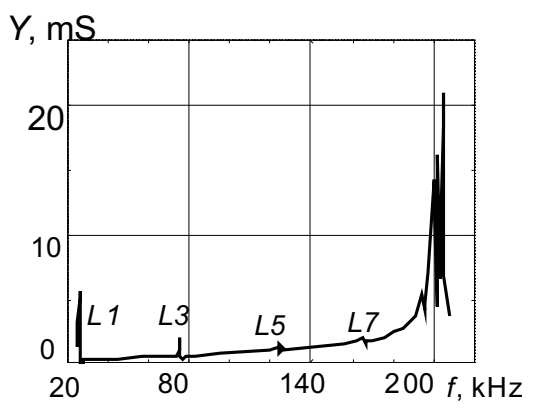

$\boldsymbol{a}$
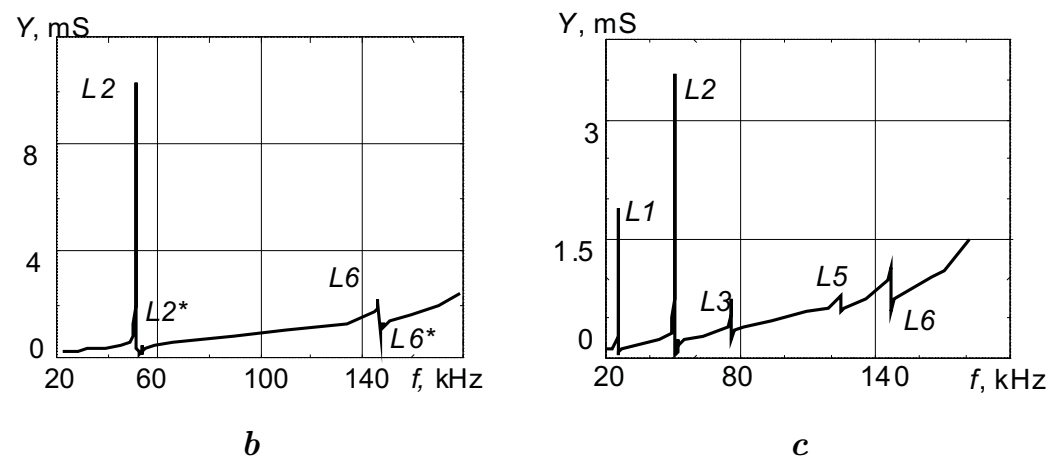

Fig. 3. Input admittance of the one bilateral electrode cut prism.
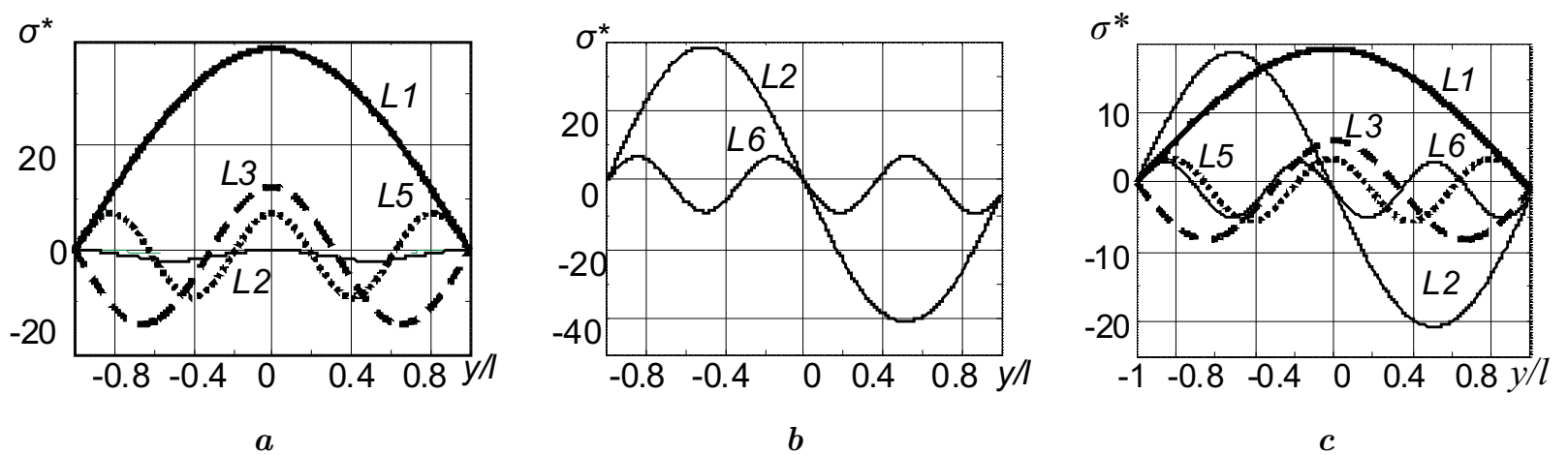

Fig. 4. Calculated stress state for bar-prism with the one bilateral electrode cut.

Fig. 4 demonstrates calculated longitudinal stresses of one bilateral cut prism for in-phase $(a)$, antiphase $(b)$, and shorted $(c)$ electrodes cases. Formulae of Ref [17], which are similar to the expression (5), were used in calculations. Abscissa axis is bar's length and ordinate axis is normalized longitudinal stress $\sigma^{*}=\sigma_{x} /\left(d_{31} E_{x 1}\right)$. For full or in-phase electrodes case the most strong is fundamental mode $L 1$, then amplitude of $L 3$ and $L 5$ modes are less in 3 and 5 times accordingly. The sign of $L 3$ mode stresses changes in $1 / 3$ distance from the edges and sign of mode $L 5$ stresses changes in $1 / 5$ distance from the edges. To increase L3 mode it is necessary to divide an electrode coating in three equal parts with bilateral cut and to load them in anti-phase. Such conclusion was made by Ref [14] authors on base of the energy method. And to increase L5 mode it is necessary to divide an electrode coating in five equal parts with bilateral cut and to load them in anti-phase.

In anti-phase case (Fig. 4, b) for prism with one bilateral electrode cut the odd modes L1, L3, L5 etc. are put down but even longitudinal modes L2, L6, L10 are selected. Stress amplitude of the selected mode $L 2$ reaches the same value which $L 1$ mode has for full electrode case. When upper and lower electrodes of one half of prism with one bilateral electrode cut are connected together or shorted (Fig. 4, c), so strong non-uniformity appears that may excite odd $L 1, L 3, L 5$ and even L2, L6 longitudinal modes. The stress amplitude for $L 1$ and $L 2$ modes are equal but in two times less then for in-phase or anti-phase cases.

Fig. 5 illustrates measured longitudinal stresses of the one bilateral cut prism for in-phase $(a)$, anti-phase $(b)$, and shorted $(c)$ electrodes cases as piezotransformer transducer ratio distribution along 


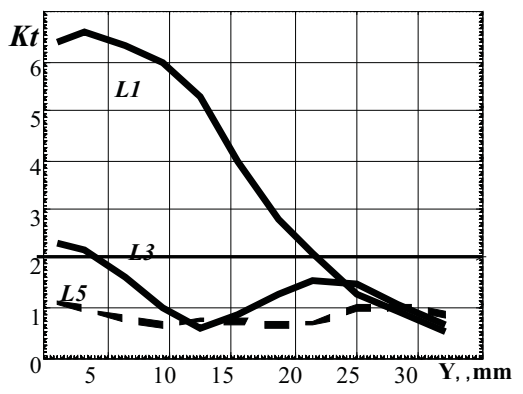

$a$

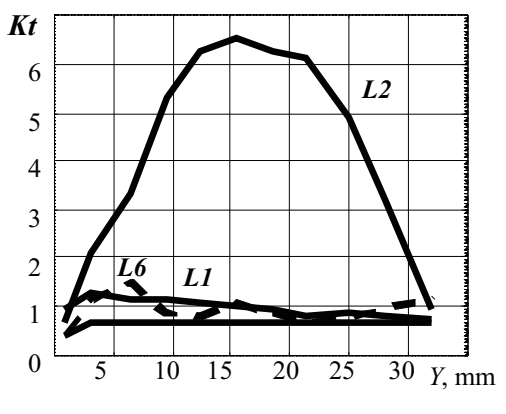

$b$

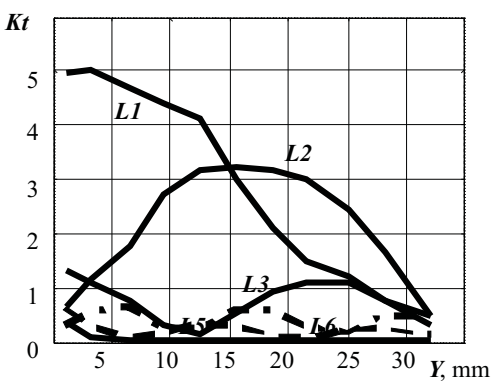

$c$

Fig. 5. Distribution of transformation ratios for bar-prism with the one bilateral electrode cut.

one-half of prism. These graphs are similar to calculated figures. Since the voltmeter does not react to potential, the sign of the transform ratios minima coincides with zero points of calculated lines.
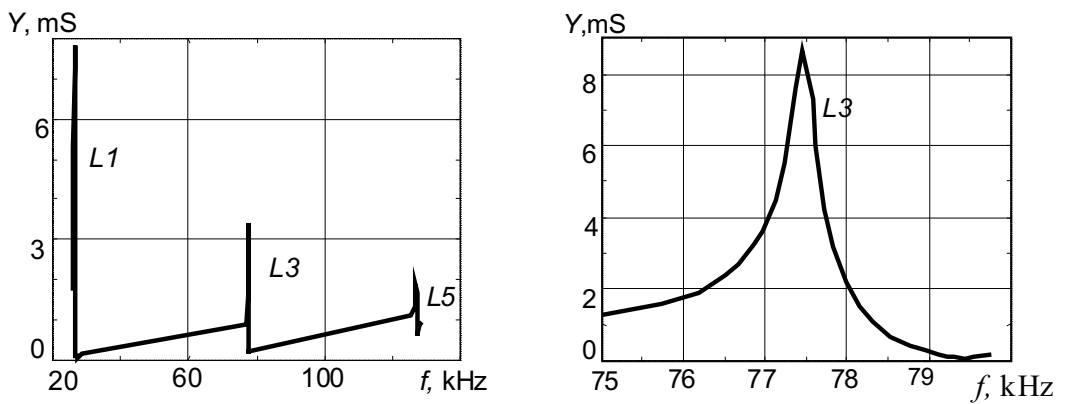

$a$

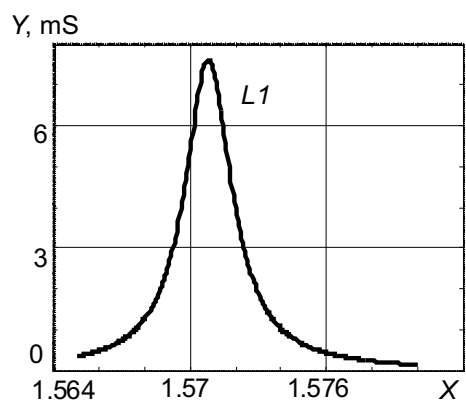

$b$

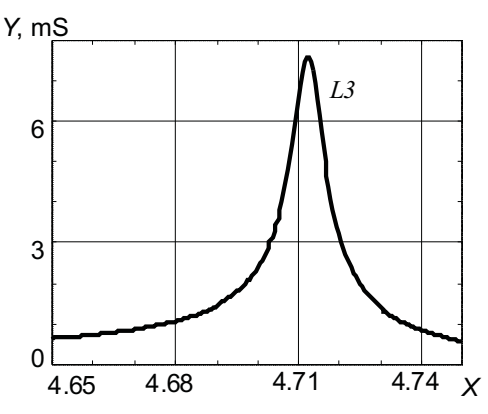

$d$

Fig. 6. Measured $(a, b)$ and calculated $(c, d)$ admittances for bar-prism with two bilateral electrode cuts.

Fig. 6 illustrates the measured $(a, b)$ and the calculated $(c, d)$ admittances for two bilateral cuts prism. Experimental data presented in the in-phase load case for L1, L3, L5 modes and frequency range $20 \div 140 \mathrm{kHz}$ (Fig. 6, a). Modes L1, L5 in an anti-phase case are not registered and measurements were carried out in narrowed range $75 \div 80 \mathrm{kHz}$ (Fig. $6, b$ ). The calculations for $L 1$ mode with in-phase electrodes (Fig. 6, c) and for L3 mode with anti-phase electrodes were made by formula (10) using. Both calculated and measured data are in good agreement.

In two bilateral electrodes cuts prism's case with 3.3 schema loading, when upper central electrode was free (open circuit), the most admittance $6 \mathrm{mS}$ had mode L3 (Fig. 7, a), while for in-phase case this parameter was $3.5 \mathrm{mS}$. Admittance of fundamental longitudinal mode $L 1$ decreased from $7.6 \mathrm{mS}$ to $1.6 \mathrm{mS}$. Modes $L 5$ and $L 7$ became entirely weak. In piezotransformer regime with free central or outer upper electrodes the transform ratios for L1 (Fig. 7,b) and L3 (Fig. 7, c) modes are almost equal values and depend on loading condition (schema S3.4 or S3.5) only. Calculated by using formula (1) 
data coincide with experimental ones. Transform ratios in the experiment were determined as the relation (19).

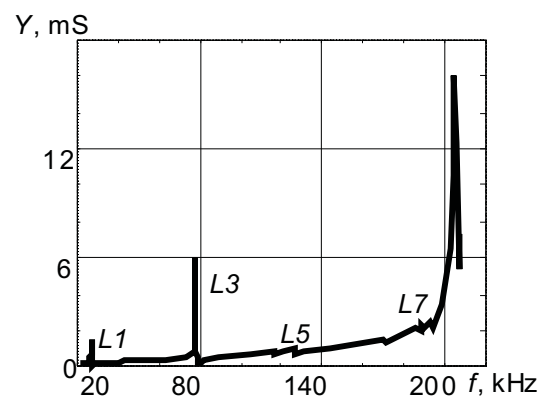

$a$

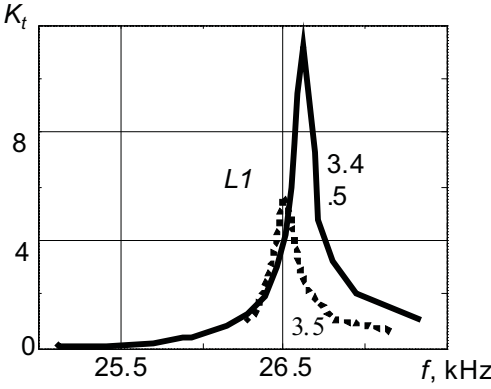

$b$

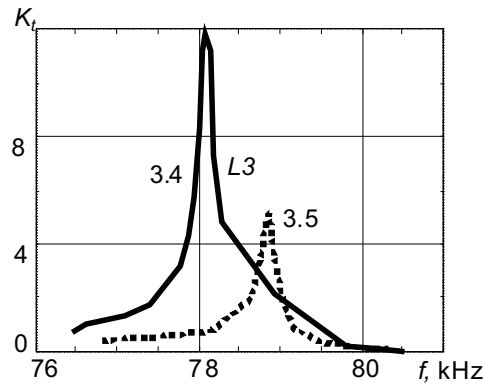

$c$

Fig. 7. Admittance $(a)$ and transform ratios for $L 1(b)$ and $L 3(c)$ modes of bar-prism with two bilateral electrode cuts.

Very interesting data were obtained for transform ratios of multi-electrode piezotransformer, when prism-bar with two bilateral cuts had tree electrode pairs - in centre, near left edge and near right edge (Fig. 8). Two left electrodes were connected with signal generator and rest electrodes were free. Transform ratios are dependent on output electrode spacing and vibration modes. For fundamental longitudinal mode $L 1$ (Fig. 8, a) central upper (curve 1) and lower (curve 2) electrodes have maximum electric potentials. A week dependence of the transform ratios from electrode spacing are observing for L3 overtone (Fig. 8, c). Most dependence of the transform ratios from electrode spacing mode L2 demonstrates (Fig. 8, $b$ ). This mode for in-phase electrodes case is absent. Two potential maxima are observing at frequencies $52.446 \mathrm{kHz}$ and $53.109 \mathrm{kHz}$.
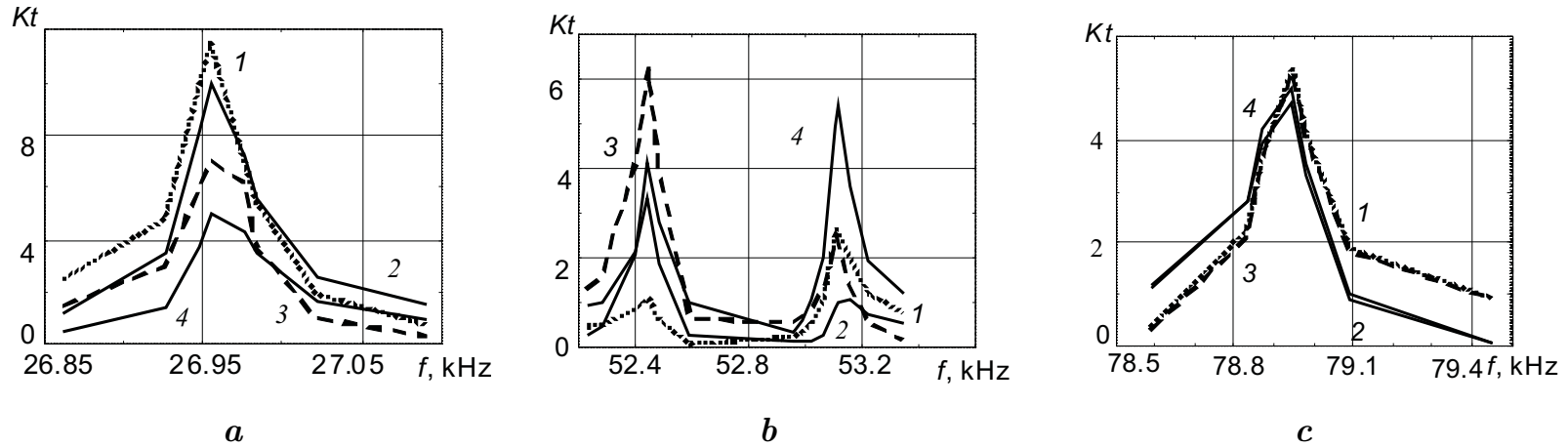

Fig. 8. The transform ratios for $L 1(a), L 2(b)$ and $L 3(c)$ modes of bar-prism multi-electrode transformer.

The reason of a resonant frequency bifurcation may be an influence of the output electrodes on input electrodes. Maxima of the transform ratio frequencies for multi-electrode transformer of $L 1$, L3 modes are higher than admittance maxima frequencies for in-phase case: $25.95 \mathrm{kHz}$ and $78.95 \mathrm{kHz}$ instead $26.268 \mathrm{kHz}$ and $77.639 \mathrm{kHz}$.

Dynamic electromechanical coupling factors (EMCF) were determined as [5-7]

$$
k_{d}^{2}=\frac{f_{a}^{2}-f_{r}^{2}}{f_{a}^{2}} \cong \frac{f_{n}^{2}-f_{m}^{2}}{f_{n}^{2}} \cong \frac{2\left(f_{n}-f_{m}\right)}{f_{n}} .
$$

In (20) $f_{r}$ and $f_{a}$ are the resonant and the anti-resonant frequencies, $f_{m}$ and $f_{n}$ are the maximum and the minimum admittance frequencies.

It was established that the square value of EMCF for anti-phase loading case may reach up to $0.7-0.8$ of the square value of EMCF of L1 mode at in-phase loading. 


\section{Conclusions}

Amplitude-frequency characteristics for piezoelectric bars with divided electrodes, which are obtained in Institute Mechanics Research Laboratory (Department of Electroelasticity), showed that electric loading regimes influence significantly the admittance, the impedance, and EMCF. A one-dimensional bar model well describes frequency properties of such complicated piezoelectric sample as prism with trapezium cross section. For experimental verification of vibration's modes, the piezotransformer transducer method elaborated in $[6,7,9]$ is very suitable.

The selected overtones can be increased and other included fundamental resonances can be oppressed with electrode dividing and non-uniform electric loading.

Experiments have been carried out with TsTBS-3 $70.3 \times 8.1 \times 6.8 / 7.1 \mathrm{~mm}$ size bar-prism. It was established that high electromechanical coupling may be obtained for bar's longitudinal overtones by means of the electrode coating dividing and anti-phase electrical loading. In shorted part electrodes case, not only odd but even longitudinal modes can be excited, which are absent for full electrodes.

The high-frequencies longitudinal overtones are masked by intensive lateral and thickness modes.

[1] Uchino K., Zhuang Yu., Ural S. O. Loss determination methodology for a piezoelectric ceramic: new phenomenological theory and experimental proposals. J. Adv. Dielectric. 1, N.1, 17-31 (2011).

[2] Ural O., Tuncdemir S., Zhuang Yu., Uchino K. Development of a high power piezoelectric characterization system and its application for resonance/antiresonance mode characterization. Jpn. J. Appl. Phys. 48, n. 5R, 056509 (2009).

[3] Uchino K., Zheng J. H., Chen Y. H. et al. Loss mechanisms and high power piezoelectric. J. Mat. Sci. 41, 217-228 (2006).

[4] Jaffe B., Cook W. R., Jaffe H. Piezoelectric ceramics. Academic Press, London (1971).

[5] Shul'ga N. A., Bolkisev A. M. The vibrations of piezoelectric bodies. Nauk. Dumka, Kiev (1990) (in Russian).

[6] Shul'ga M. O., Karlash V. L. Resonant electromechanical vibrations of piezoelectric plates. Nauk. Dumka, Kiev (2008) (in Ukrainian).

[7] Karlash V. L. Resonant electromechanical vibrations of piezoelectric plates. Int. Appl. Mech. 41, n.7, 709-747 (2005).

[8] Karlash V. L. Energy losses in piezoceramic resonators and its influence on vibrations' characteristics. Electronics and communication. 19, n. 2(79), 82-94 (2014).

[9] Karlash V. L. Methods of determination of coupling factors and energy losses at piezoceramics resonator's vibrations. Acoustic bulletin. 15, n. 4, 24-38 (2012) (in Ukrainian).

[10] Karlash V. L. Modeling of energy-loss piezoceramic resonators by electric equivalent networks with passive elements. Mathematical modeling and computing. 1, n. 2, 163-177 (2014).

[11] Erhart J. Parameters and design optimization of the ring piezoelectric ceramic transformer. Adv. Dielect. 5, n. 3, $1550022(2015)$.

[12] Erhart J., Tutu S. Effective electromechanical coupling for the partially electroded ceramic resonators of different geometries. Ann. "DUNAREA DE JOS" Univ. of Galati Fascicle IX. Metallurgy and Material Science. N. 2, 7-16 (2015).

[13] Rogacheva N. N. The dependence of the electromechanical coupling coefficient of piezoelectric elements on the position and size of the electrodes. Appl. Math. Mech. 65, n. 2, 317-326 (2001).

[14] Andrushchenko V. O., Boryseyko O. V., Nemchenko D. S., Ulitko I. A. Experimental investigation of the energy transducing affectivity at piezoceramic bar with divided electrodes and control electric exiting resonant vibrations. Acoustic symposium "CONSONANCE-2009", Kyiv, September 29 - October 1, 2009. Proceedings. 38-43 (2009) (in Ukrainian).

[15] Van der Veen B. The equivalent network of a piezoelectric crystal with divided electrodes. Phillips. Res. Rep. 11, 66-79 (1956).

Mathematical Modeling and Computing, Vol.3, No.1, pp.1-11 (2016) 
[16] Munk E. C. The equivalent electrical circuit for radial modes of a piezoelectric ceramic disk with concentric electrodes. Phillips Res. Rep. 20, 170-189 (1965).

[17] Karlash V. L. Forced electromechanical vibrations of rectangular piezoceramic bars with sectionalized electrodes. Int. Appl. Mech. 49, n. 3, 360-368 (2013).

[18] Mezheritsky A. V. Elastic, dielectric and piezoelectric losses in piezoceramics; how it works all together. IEEE Trans UFFC. 51, n. 6, 695-797 (2004).

\title{
Моделювання й експериментальна верифікація вимушених коливань тонких багатоелектродних п'єзокерамічних стрижнів
}

\author{
Безверхий О. І., Зінчук Л. П., Карлаш В. Л. \\ Інститут механіки ім. С. П. Тимошенка НАН Украӥни \\ вул. Несторова, 3, 03057, Київ, Україна
}

\begin{abstract}
Проаналізовано вимушені коливання багатоелектродних п'єзокерамічних стрижнів. Побудовано аналітичну модель для тонкого й вузького п'єзокерамічного стрижня з трьома парами розділених електродів на горішній і нижній основних поверхнях. Отримано формули вхідного адмітансу, характеристичних (резонансних і антирезонансних) частот, а також коефіцієнтів трансформації. Досліджувались основні моди коливань і їхні парні та непарні обертони. Нова проста експериментальна методика 3 додатковою комутацією дає змогу вивчати багато параметрів резонатора: адмітанс, імпеданс, фазові кути, компоненти потужності тощо. Експерименти велися із стрижнями-призмами розміром $70.3 \times 8.1 \times 6.8 / 7.1$ мм із кераміки ЦТБС- 3 . Встановлено, що високий електромеханічний зв'язок на обертонах поздовжніх коливань стрижня можна отримати через розділення електродного покриття і протифазного електричного навантаження. У разі коротко замкнутих окремих електродів можуть збуджуватися не тільки непарні, а й парні поздовжні моди, яких за суцільних електродів немає.
\end{abstract}

Ключові слова: багатоелектродний п'єзокерамічий стрижень, вимушені коливання, електромеханічний зв'язок, вхідна провідність, коефічієнт трансформацї̈.

2000 MSC: 74-05, 74F $15,74 \mathrm{H} 45$

UDC: $534.1: 537.226 .86: 539.3$ 